\title{
The role of TIM-containing molecules in airway disease and their potential as therapeutic targets
}

\author{
This article was published in the following Dove Press journal: \\ Journal of Inflammation Research \\ 13 August 2012 \\ Number of times this article has been viewed
}

\author{
Isabel Vega-Carrascal \\ Emer P Reeves \\ Noel G McElvaney \\ Respiratory Research Division, \\ Department of Medicine, Royal \\ College of Surgeons in Ireland, \\ Education and Research Centre, \\ Beaumont Hospital, Dublin, Ireland
}

Correspondence: Emer P Reeves Respiratory Research Division, Department of Medicine, Royal College of Surgeons in Ireland, Education and Research Centre, Beaumont Hospital, Dublin 9, Ireland

Tel +353 । 8093877

$\mathrm{Fax}+353$ । 8093808

Email emerreeves@rcsi.ie

\begin{abstract}
T cell immunoglobulin and mucin-domain (TIM)-containing molecules have emerged as promising therapeutic targets to correct abnormal immune function in several autoimmune and chronic inflammatory conditions. Despite the initial discovery linking TIM-containing molecules and the airway hyperreactivity regulatory locus in mice, there is a paucity of studies on the function of TIM-containing molecules in lung inflammatory disease. Initially, studies were limited to mice models of asthma. More recently however, TIM-containing molecules have been implicated in an ever-expanding list of airway conditions that includes pneumonia, tuberculosis, influenza, sarcoidosis, lung cancer, and cystic fibrosis. This present review discusses the role of TIM-containing molecules and their ligands in the lung, as well as their potential as therapeutic targets in airway disease.
\end{abstract}

Keywords: $\mathrm{T}$ cell immunoglobulin and mucin-domain, inflammation, galectin-9, airway disease

\section{Introduction}

$\mathrm{T}$ cell immunoglobulin and mucin-domain (TIM) molecules are key regulators of immune responses. ${ }^{1-4}$ TIM proteins have also been associated with several human inflammatory conditions, ${ }^{3,5}$ including rheumatoid arthritis, ${ }^{6}$ asthma, ${ }^{7}$ systemic lupus erythematosus, ${ }^{1}$ multiple sclerosis,${ }^{8}$ diabetes, ${ }^{9}$ and, more recently, in tumor ${ }^{10,11}$ and antimicrobial immunity. ${ }^{12}$ However, the role of TIM-containing molecules in airway disease is only beginning to be unraveled. In this review, we consolidate the literature to discuss the prospective role of TIM-containing molecules as key inflammatory mediators with the potential to be utilized as therapeutic targets in the treatment of a variety of human diseases. Our literature review was carried out using the MEDLINE ${ }^{\circledR}$ database (from 1987 to 2012), ${ }^{13}$ Google Scholar, ${ }^{14}$ and The Cochrane Library ${ }^{15}$ database using several appropriate generic terms.

\section{TIM structure and signaling}

The TIM gene family is encoded on chromosome 11B1.1 in mice (TIM1-8) and chromosome $5 q 33.2$ in humans. There are four TIM proteins characterized in mice - TIM-1, TIM-2, TIM-3, and TIM-4 - but only three members of the family have been identified in humans: TIM-1, TIM-3, and TIM-4. Human TIM-3 shares $63 \%$ homology with mouse TIM-3 and TIM-4 shares 49\% homology with the mouse ortholog TIM-4. In contrast, human TIM-1 does not seem to have a clear ortholog in mouse as it shares $42 \%$ and $32 \%$ amino-acid sequence with murine TIM-1 and TIM-2, respectively. ${ }^{16}$ All TIM-containing 
molecules share a similar structure as type I membrane proteins, consisting of an N-terminal immunoglobulin variable (IgV)-like domain, a mucin-like domain, a transmembrane region, and an intracellular tail (Figure 1).

Human TIM IgV-like domains share 40\% homology and are cysteine rich, suggestive of a highly cross-linked structure ${ }^{17}$ In contrast, the mucin-domain presents in an extended conformation. The size of the mucin-domain varies depending on the receptor, with TIM-3 being the shortest. TIM-1 and TIM-3 are involved in intracellular signaling through tyrosine-phosphorylation motifs in the cytoplasmatic domain, whereas TIM-4 does not contain a conserved motif, indicating that it exerts its function by association with other receptors. An important feature of TIM-containing molecule structure is the high level of glycosylation that enables ligand binding ${ }^{17}$ and increases resistance to proteolytic cleavage. All TIM receptors are predicted to be N-glycosylated in the immunoglobulin (Ig)domain and at different positions close to the membrane, and O-glycosylated in the mucin-domain. However, the level of glycosylation varies from one predicted site in TIM-3 to up to 57 in TIM-1 (Figure 1).

TIM-1 was initially identified as hepatitis A virus receptor in monkeys ${ }^{18}$ and in humans. ${ }^{19}$ It was also cloned as kidney injury molecule-1. ${ }^{20} \mathrm{TIM}-1$ is overexpressed in injured renal epithelium and can be cleaved off the cell membrane by metalloproteases. ${ }^{21}$ Shedded TIM-1 can be detected in urine after kidney injury and it has been proposed as a urinary marker of renal injury. ${ }^{20,22}$ Interest in TIM-containing molecules has grown dramatically since the discovery of differential TIM expression in Thelper ( Th) cells and their immunomodulatory properties. TIM- 1 is expressed in Th- 2 cells, whereas TIM- 3 is found in Th- 1 cells. ${ }^{8}$ TIM signaling has mostly been studied in Th cells in mice. However, the TIM-1 signaling mechanisms in Th-2 cells are poorly understood. Studies in mice suggest that, in contrast to TIM-3, TIM-1 acts as a positive regulator of Th-2 cell function, ${ }^{23}$ whereas TIM- 2 has been shown to act as a negative regulator of Th- 2 responses. ${ }^{24} \mathrm{~A}$ TIM-2 human ortholog has not been identified, despite its close sequence homology with murine TIM-1.

Unlike other members of the TIM family, TIM-4 is not expressed in T cells but is found in antigen-presenting cells, including dendritic cells and macrophages. ${ }^{16}$ The exact role of TIM-4 is not fully understood. TIM-4 in macrophages has been found to bind phosphatidylserine on apoptotic cells, mediating apoptotic body clearance ${ }^{25,26}$ and raising the possibility of a role in the development of tolerance. ${ }^{27}$ In addition, TIM-4 is believed to bind to TIM-1 or self-ligate and act as a co-stimulatory molecule of $\mathrm{T}$ cell function. ${ }^{4}$ TIM-4 function in T cells is complex and appears to work in a bimodal fashion. Both inhibitory and stimulatory responses have been reported depending on the activation status of the $\mathrm{T}$ cell, the level of TIM-4 expression, and whether co-stimulatory cells express TIM-4.,16 Thus, TIM-4 is capable of modulating the immune response despite the absence of downstream cytosolic signaling motifs.

TIM-3 signaling in Th-1 cells is better characterized. Galectin-9 binds to TIM-3 in a glycosylation-dependent

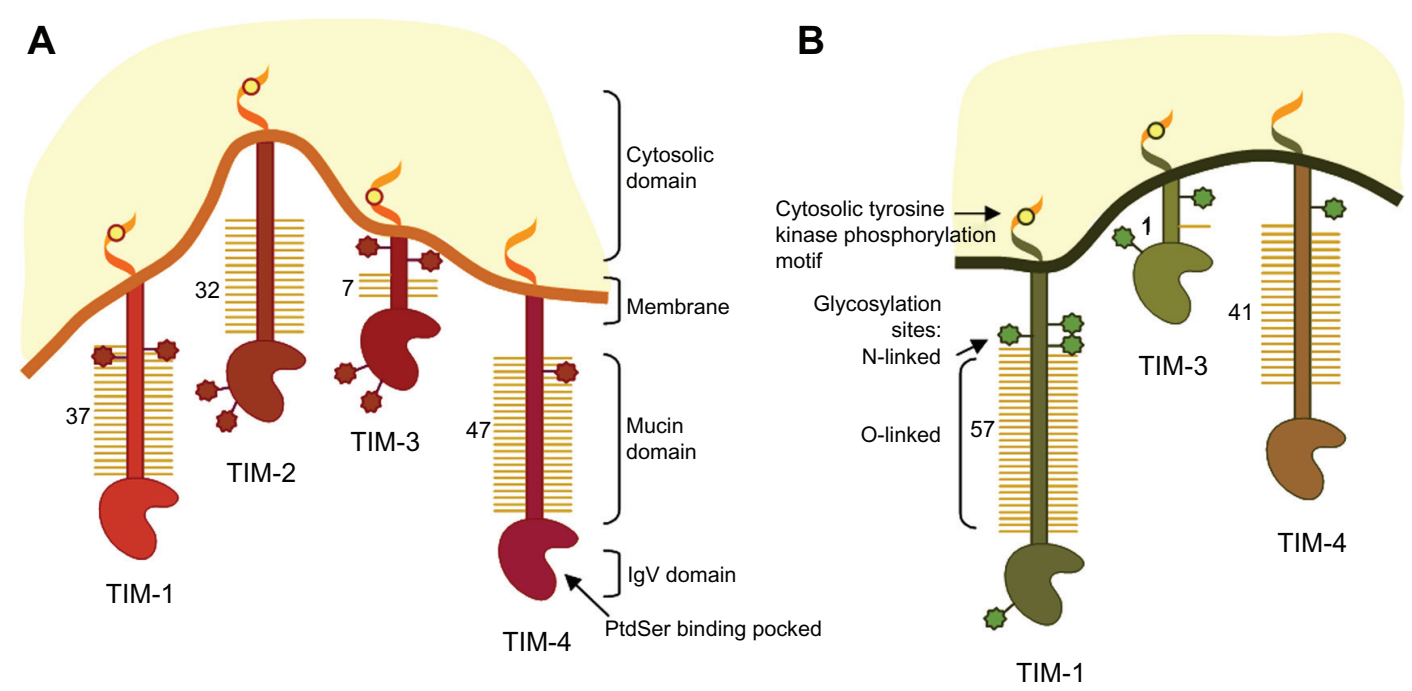

Figure I Schematic representation of mouse and human T cell immunoglobulin and mucin-domain (TIM)-containing molecules.

Notes: Protein structure and positions of the glycosylated sites of mouse TIM-I, $-2,-3$ and -4 and human TIM-I, -3 and -4 are shown. N-glycosylation in the immunoglobulindomain and at different positions close to the membrane and O-glycosylation in the mucin-domain are positioned approximately.

Abbreviations: IgV, immunoglobulin variable; PtdSer, phosphatidylserine. 


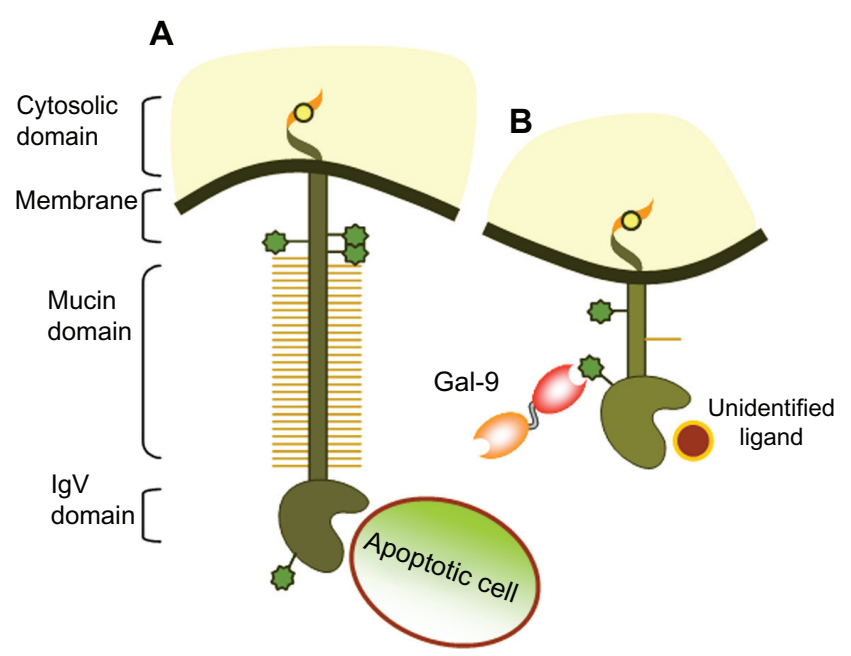

Figure 2 Schematic representation of T cell immunoglobulin and mucin-domain (TIM)containing proteins and their ligands. (A) TIM-I can bind to phosphatidylserine on apoptotic bodies through the FG-CC' binding region in the $\mathrm{N}$-terminal immunoglobulin variable (IgV) domain conferring phagocytic characteristics to epithelial cells. TIM-I can also bind to soluble TIM-4 or ligate to itself, leading to $\mathrm{T}$ cell activation and T-helper (Th)-2 expansion. (B) TIM-3 binds to galectin-9 (Gal-9) through N-linked carbohydrates in the IgV domain, driving a Th-I-mediated inflammatory response. Note: The ligand binding to the FG-CC' cleft on the opposite side of the $\lg \bigvee$ domain has not yet been identified.

manner (Figure 2). Although the downstream signaling events remain poorly characterized, TIM-3 activation causes phosphorylation of the tyrosine motif Y265 in the cytosolic domain. ${ }^{28}$ Other tyrosine residues of TIM-3 appear to be responsible for signal transduction in $\mathrm{T}$ cell receptordependent mechanisms. ${ }^{29}$ TIM-3 engagement by galectin- 9 has been shown to induce apoptosis of Th- 1 cells. ${ }^{30}$ Blockade of galectin-TIM-3 interaction induced an exacerbation of Th-1-driven immune response and increased the level of macrophage activation in a mouse model of autoimmune disease. ${ }^{31}$ In humans, TIM-3 blockade with monoclonal antibodies revealed that human TIM-3 signaling regulates cytokine expression at the transcriptional level rather than controlling Th-1 cell expansion as it does in mice. ${ }^{32}$ Collectively, these data suggest an inhibitory role for TIM-3 in Th-1-driven immunity.

TIM-3 has also been reported to play a role in the induction of peripheral tolerance. Blockade of TIM-3 function by administration of soluble TIM-3 prevented the development of tolerance in Th-1 cells. ${ }^{33}$ Furthermore, TIM-3-deficient mice are resistant to tolerance induction by administration of high-dose antigen. ${ }^{33}$ TIM-3 has been shown to regulate both auto- and allo-immune tolerance by modulating T-regulatory cell-mediated inflammatory responses. ${ }^{9}$ This TIM-3 function has been confirmed in a murine model of graft-versus-host disease. ${ }^{34}$ Perhaps one of the most exciting functions of TIM-3 is its role in $\mathrm{T}$ cell exhaustion during chronic viral infections and in tumor immunity (Figure 3). Indeed, blockade of TIM-3 in these settings restored normal $\mathrm{T}$ cell function. ${ }^{10,11}$ More recently, it was discovered that TIM-3 is also expressed in other subsets of T cells, and cells from the innate immune system including monocytes, dendritic cells, mast cells, and microglia. ${ }^{3,4}$ Thus, the role of TIM-3 is not limited to the adaptive immune response. For instance, TIM-3 is involved in macrophage phagocytic ${ }^{35}$ and bactericidal activity. ${ }^{12,36}$

In addition to the immunomodulatory properties, TIM-containing molecules also play an important role in apoptotic body clearance via phosphatidylserine recognition. ${ }^{27}$ TIM- $-{ }^{26}$ and TIM- $1^{25}$ have been shown to bind to phosphatidylserine and mediate phagocytosis of apoptotic cells. More recently, it was demonstrated that TIM-3 presence in the phagocytic cup is required for apoptotic clearance by macrophages. ${ }^{35}$ The expression of TIM receptors confers phagocytic properties even in "nonprofessional" phagocytic cells. Indeed, TIM-1 expression in endothelial cells has been reported to confer phagocytic capacity to this cell type. ${ }^{3,37}$

\section{Galectin-9 signaling through TIM-3}

Galectin-9 was identified as the first ligand of TIM-3. ${ }^{30}$ In line with its lectin nature, galectin-9 binds to TIM-3 in a carbohydrate-dependent manner, interacting with the $\mathrm{N}$-glycosylated site in the IgV domain. Galectins have been shown to regulate immune homeostasis and inflammation. ${ }^{38}$ Mammalian galectins comprise a large family of S-lectin proteins characterized by their affinity for $\beta$-galactosidase sugars and the conserved specific sequence motif in the carbohydrate recognition domain (CRD). ${ }^{39}$

Human galectins have been grouped into three classes according to their structure (Figure 4): ${ }^{40}$ (1) prototypical galectins, which contain a single CRD and may appear associated in the form of homodimers; (2) chimeric galectins, which contain a single CRD and a long amino-terminal domain; and (3) tandem-repeat galectins, which contain two CRD domains linked by a small peptide chain. Galectin-9 belongs to the tandem-repeat class. To date, three galectin-9 isoforms have been identified that only differ in the length of the polypeptide linker region (Figure 5). The short-size galectin-9 has a peptide linker of 14 amino acids and the medium- and the long-size forms have a linker of 26 and 58 amino acids, respectively. ${ }^{41}$ This relatively long polypeptide chain makes galectin-9 very susceptible to proteolytic cleav- 
A

B

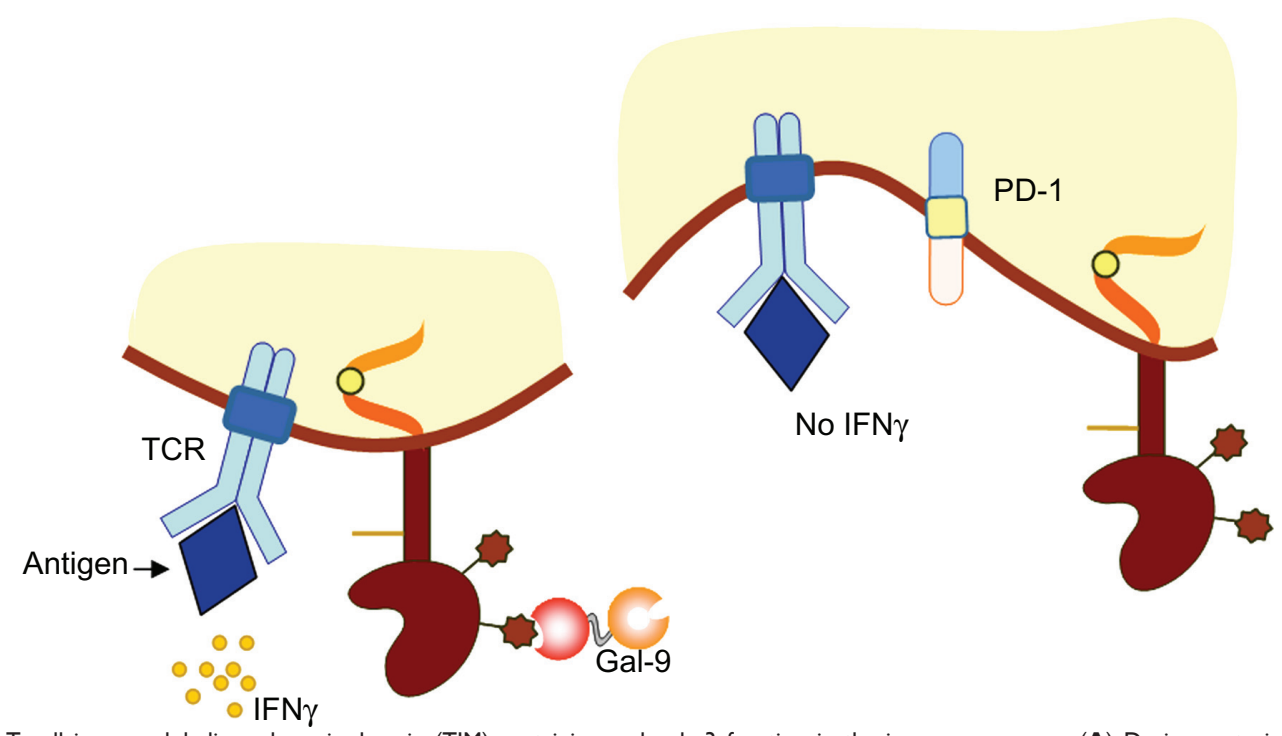

Figure 3 Model of T cell immunoglobulin and mucin-domain (TIM)-containing molecule-3 function in the immune response. (A) During acute inflammation, TIM-3 is expressed on terminally differentiated interferon-gamma (IFN- $\gamma$ )-producing CD4+ and CD8+ T cells. TIM-3-expressing T cells undergo apoptosis following recognition of the TIM-3 ligand galectin-9 (Gal-9). (B) During chronic inflammation, dysfunctional or exhausted CD8+ T cells express both TIM-3 and programmed death-I receptor (PD-I). Note: Combined targeting of the PD- I/PD-ligand I and TIM-3/TIM-3 ligand pathways restores CD8+ T cell effector function and ameliorates chronic disease. Abbreviation: TCR, T cell receptor.

age, ${ }^{42}$ resulting in inactivation of the molecule. ${ }^{43}$ Recently, a recombinant form of galectin-9 lacking the linker chain has been shown to be functional and resistant to proteases (Figure 5). ${ }^{42}$

Galectin-9 was first identified in embryonic mouse kidney and found to be ubiquitously expressed in mouse and rat tissue. ${ }^{44}$ Galectin- 9 is also widely distributed in human tissues and expressed in several cell types. ${ }^{45}$ Galectin- 9 expression has been reported in epithelial tissues such as endometrium, ${ }^{46}$ cervix, ${ }^{47}$ and intestine. ${ }^{48}$ Galectin- 9 expression in the oral-nasopharyngeal tract has been located to fibroblasts in nasal polyps, ${ }^{49}$ periodontal ligaments in the oral cavity, ${ }^{50}$ and Epstein-Barr virus-related nasopharyngeal carcinoma cells. ${ }^{51}$ Galectin- 952 is also abundantly expressed in human endothelial cells ${ }^{52,53}$ and melanocytes ${ }^{54}$ and is broadly expressed in the immune system, including in bone marrow, the spleen, the thymus, and lymph nodes. Within immune cells, galectin-9 expression has been demonstrated in myeloid lineage cells ${ }^{55}$ including Kupffer cells, ${ }^{56}$ microglia, ${ }^{57}$ astrocytes, ${ }^{58}$ dendritic cells, ${ }^{59}$ and macrophages. ${ }^{12}$ Galectin-9 has also been shown to be constitutively expressed in mast cells $^{54}$ and, to a lesser extent, in the Jurkat $\mathrm{T}$ lymphocyte cell line. ${ }^{41}$ Regulatory $\mathrm{T}$ cells also express galectin- $9 .{ }^{60}$ Although galectin-9 was not detected in human promyelocytic leukemia cells, it was found to be expressed in neutrophils in the lung of ovalbumin-challenged mice. ${ }^{61}$ The most interesting feature of galectin- 9 expression is that, although most immune cells exhibit constitutive expression, the extent of expression depends on the stage of cell activation and differentiation. ${ }^{62}$ For instance, galectin-9 mRNA expression has been reported to be induced in peripheral blood monocytic cells after allergen stimulation. ${ }^{45}$ Galectin- 9 expression is also raised in eosinophils from hypereosinophilic patients. ${ }^{63}$

It has been proposed that galectin- 9 may have a complex role in inflammation homeostasis by exerting pro- and antiinflammatory events depending on either the concentration at sites of inflammation or cell type. ${ }^{64}$ Galectin- 9 binding to TIM-3 has been shown to reduce interferon-gamma production by inducing apoptosis of Th- 1 cells. ${ }^{30}$ Conversely, galectin-9 treatment induced tumor necrosis factor-alpha production by mast cells. ${ }^{65}$ Thus, galectin-9/TIM-3 signaling can initiate or terminate the inflammatory response by positively regulating maturation of innate cells, antigen presentation and pathogen clearance, and limiting an excessive immune response, especially that mediated by T cells. ${ }^{66}$

Disruption of galectin-9-TIM-3 interaction is commonly used to examine the mechanisms behind this signaling axis in several models of disease. Figure 6 summarizes the different approaches adopted to block TIM-3 engagement by galectin-9 via N-glycosylation of the receptor. Intriguingly, galectin-9 interaction with a yet unidentified membrane glycoprotein has recently been shown to block Th-17 function via O-glycosylation. In addition to TIM-3, galectin-9 has 


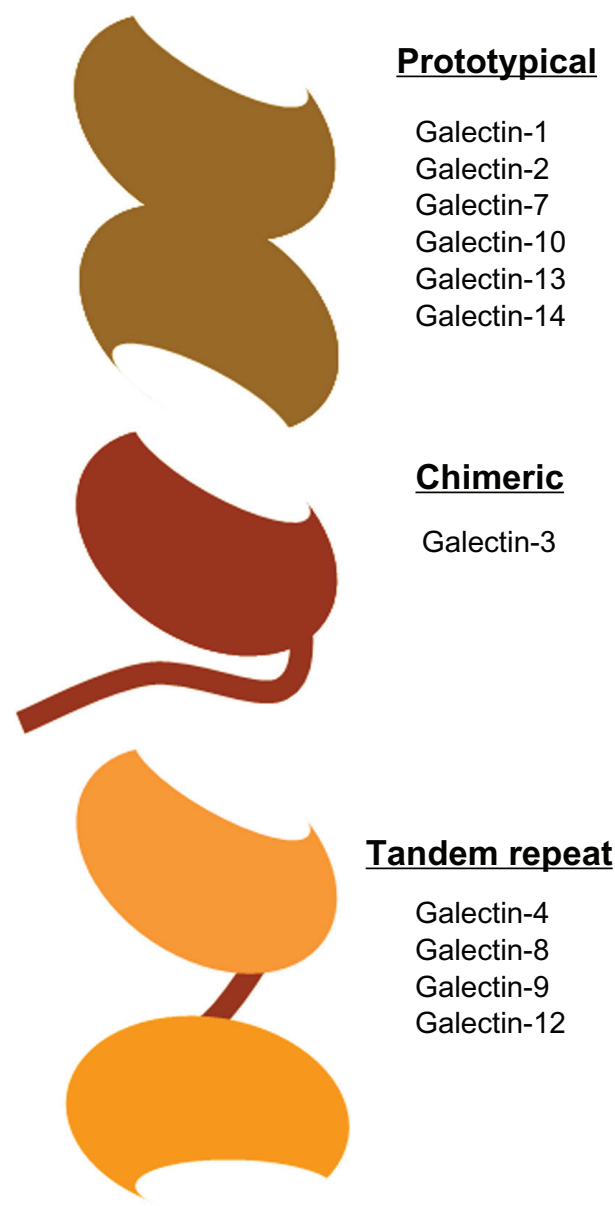

Figure 4 The different types of galectins in humans.

Notes: Human galectins have been classified according to their structure into prototypical, chimeric, and tandem repeat. The oval domain represents the carbohydrate recognition domain (CDR). Prototypical galectins such as galectin-I contain only one type of CDR, chimeric galectin-3 contains a single CDR attached to a long polypeptide chain, whereas tandem-repeat galectins such as galectin- 9 consist of two different CDRs connected by an inter-domain polypeptide linker.

also been reported to bind to other glycoproteins containing $\beta$-galactosides in their structure, including CD44, a surface receptor expressed on epithelial cells involved in cell-matrix adhesion and interaction; ${ }^{67,68} \mathrm{IgE} ;{ }^{69}$ glucose transporter $2 ;^{70}$ and Epstein-Barr virus latent membrane protein-1. ${ }^{51}$

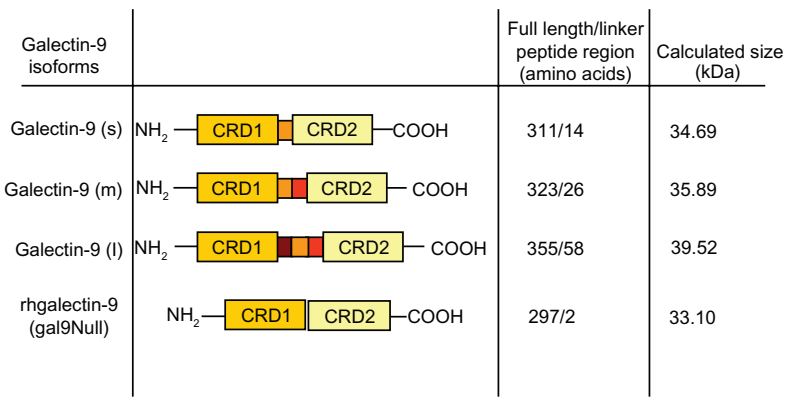

Figure 5 Schematic representation of galectin-9 isoforms structure.

Notes: Sequencing of galectin-9 revealed isoforms of different sizes differing only in the linker peptide region length (small [s], medium [m], and long [l]). The structure of proteolytically resistant recombinant galectin-9 (rhgalectin-9 [gal9Null]) is also shown. ${ }^{42}$ Abbreviation: CRD, carbohydrate recognition domain.

\section{TIM-containing molecules in airway disease}

The TIM gene family was located to a section of chromosome 11 in mice syntenic to human chromosome 5q23-35. ${ }^{71}$ This region was identified as a novel gene locus for human atopic disease (ie, asthma, allergy, and eczema) in a study comparing congenic mouse strains with different susceptibility to asthma. Despite the initial discovery linking TIM and the airway hyperreactivity regulatory locus (Tapr) in mice, ${ }^{71}$ there is a paucity of studies on the function of TIM-containing molecules in lung inflammatory disease. Most of the existing studies were carried out in mice models of asthma. More recently, TIM-containing molecules have been implicated in sarcoidosis, pneumonia, tuberculosis, influenza, and cystic fibrosis (Table 1).

\section{TIM-I in airway disease}

Although the role of TIM-1 and TIM-3 in the development of lung allergy has recently been questioned in a study using knockout mice, ${ }^{72}$ TIM-1 expression has been reported to be upregulated in the lung of asthmatic mice. ${ }^{73}$ Indeed, blockade of mouse TIM-1 decreased the Th-2-type immune response and airway inflammation in a murine model of asthma in a number of studies. ${ }^{23,74,75}$ Blockade of TIM-1 with anti-TIM-1 antibody during initial challenge with antigen prevented air-
A

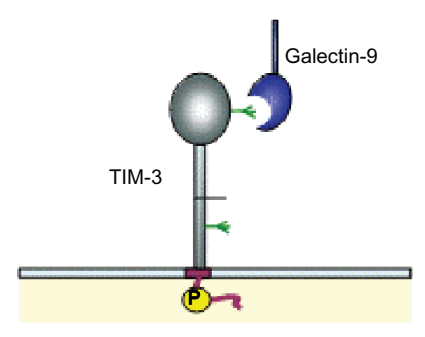

C

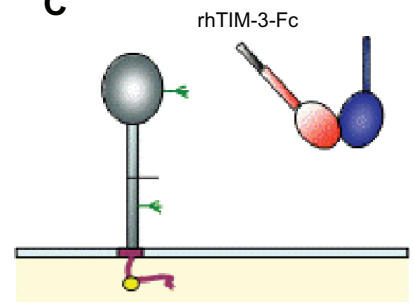

B

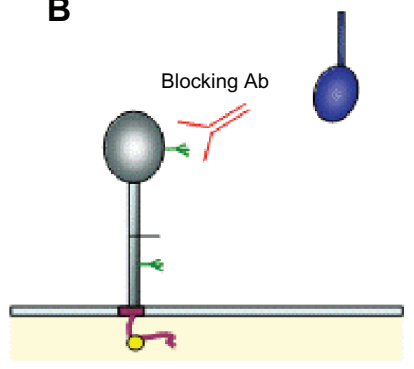

D

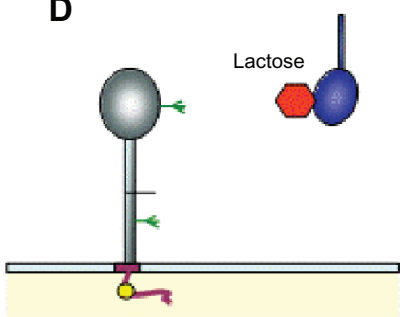

Figure 6 Schematic representations of $T$ cell immunoglobulin and mucindomain (TIM)-containing molecule-3-galectin-9 interaction disruption strategies. (A) Galectin-9 binds to the TIM-3 immunoglobulin variable domain via carbohydrate interactions. ${ }^{30}$ (B) Blockade of TIM-3 by anti-TIM-3 antibody (Ab). (C) Soluble human recombinant TIM-3-Fc chimeric protein (rhTIM-3-Fc) acts as a galectin-9 scavenger receptor, preventing TIM-3-galectin-9 interaction. (D) Galectin-9 preferentially binds to excess lactose in solution due to galactosidase affinity. 
way hyperresponsiveness in a mouse model. ${ }^{74}$ Using a similar approach, a second group reported that administration of antiTIM-1 antibody between sensitization and allergen exposure also reduced airway hyperresponsiveness. ${ }^{23}$ Interestingly, TIM-1 ligation with monoclonal antibodies induced either positive or negative effects in a mouse allergy model, depending on the antibody. Antibodies recognizing the stalk or $\mathrm{IgV}$ domain attenuated inflammation, indicating that ligation of this TIM-1 region promotes inhibitory functions. In contrast, antibodies directed against the mucin-domain activated the inflammatory response. ${ }^{75}$ Therefore, therapeutic use of antiTIM-1 antibodies in asthma emerges as a promising novel treatment approach, although special attention to the TIM-1 epitope recognized by the antibody is required. Consistent with the previous results, antagonism of human TIM-1 in a humanized murine model of experimental asthma has been shown to have positive therapeutic effects. ${ }^{76}$ In this study, blockade of TIM-1 with A6G2, an antibody against the $\mathrm{IgV}$ domain, ameliorated inflammation and airway hyperresponsiveness in severe combined immunodeficiency mice adoptively transferred with peripheral blood monocytic cells from asthmatic patients. The effects of TIM-1 inhibition were exerted via suppression of Th-2 cell proliferation and cytokine production, providing encouraging data in support of the use of TIM-1 targeted antibodies for the treatment of asthma.
Despite the increasing body of work in mouse models of lung disease, there are virtually no studies in humans supporting the role of TIM-1 in airway inflammation (Table 1). Recently, T cells obtained from peripheral blood and bronchoalveolar lavage (BAL) fluid of non- Löfgren sarcoidosis patients exhibited lower TIM-1 expression than those of sarcoidosis patients with Löfgren. ${ }^{77}$ Non-Löfgren patients exhibit a marked Th-1 inflammatory response and often present with a less favorable prognosis than Löfgren patients. Since an imbalance towards a Th-1 phenotype is believed to be the hallmark of airway inflammatory response in sarcoidosis, the study by Idali and colleagues suggested that downregulation of TIM-1 in Th cells was linked to a higher Th-1 response. ${ }^{77}$ However, TIM-1 regulatory properties in airway disease are not limited to $\mathrm{T}$ cells, as it has been shown that TIM-1 engagement in natural killer cells exacerbated lung injury in a bleomycin model of pulmonary fibrosis by suppressing interferon-gamma production. $^{78}$

Clearly, a more detailed knowledge of the exact mechanisms underpinning TIM-1 signaling in airway disease is required before expanding the findings obtained from murine models to human studies. Alternatively, a better understanding of the molecular pathways underlying TIM-1 function may open a new area of research involving development of agonistic and/or antagonistic modulators of TIM-1

Table I T cell immunoglobulin and mucin-domain (TIM)-containing molecules in airway disease

\begin{tabular}{|c|c|c|c|}
\hline Disease & TIM protein & Function & References \\
\hline \multirow[t]{10}{*}{ Asthma } & TIM-I (m) & Blocking TIM-I antibody reduced Th-2-driven allergic response & 23 \\
\hline & TIM-I (m) & Antagonistic TIM-I antibody increased Th-2-driven allergic response & 74 \\
\hline & TIM-I (m) & $\begin{array}{l}\text { Epitope-dependent effect of TIM-I antibodies on Th-2 response, causing exacerbation } \\
\text { or inhibition of airway inflammation }\end{array}$ & 75 \\
\hline & TIM-3 (m) & Blocking antibody administration reduced Th-2-driven allergic response & 86 \\
\hline & TIM-I (m) & Expression increased in T cells & 73 \\
\hline & TIM-3 (m) & Expression increased in T cells & 87 \\
\hline & TIM-3 $(\mathrm{m}, \mathrm{h})$ & $\begin{array}{l}\text { Defective apoptotic clearance induces airway hyperresponsiveness. Dependent on } \\
\text { TIM-3 polymorphism }\end{array}$ & 88 \\
\hline & TIM-I (h) & Antagonistic antibody reduced Th-2 response in a humanized asthma mouse model & 76 \\
\hline & TIM-2 (m) & TIM-2-deficient mouse demonstrate exacerbated Th-2 response in asthma model & 7 \\
\hline & TIM-I/3 (h) & TIM-3 and TIM-I are not essential for airway hyperresponsiveness & 72 \\
\hline Sarcoidosis & TIM-I (h) & $\begin{array}{l}\text { Reduced expression in T cells of non-Löfgren's patients is in agreement with an } \\
\text { exaggerated Th-I response }\end{array}$ & 77 \\
\hline Sarcoidosis & TIM-3 (h) & Reduced expression in T cell in BAL and blood correlated negatively with CD4/CD8 ratio & 77 \\
\hline Tuberculosis & TIM-3 (m/h) & TIM-3 interacted with galectin-9 on macrophages to restrict intracellular bacterial growth & 12 \\
\hline Cystic fibrosis & TIM-3 (h) & Constitutive upregulation in bronchial epithelial cells induced IL-8 production & 91 \\
\hline Pneumonia & TIM-3 (m) & Galectin-9 intraperitoneal administration reduced IL- I7 production and bacterial clearance & 89 \\
\hline Pulmonary fibrosis & TIM-I (m) & Co-stimulation on NKTs enhances the production of IL-4 and inhibits production of IFN- $\gamma$ & 78 \\
\hline Influenza & TIM-3 (m) & $\begin{array}{l}\text { Blocking TIM-3-galectin-9 interaction resulted in improved immune response against } \\
\text { influenza A virus }\end{array}$ & 90 \\
\hline
\end{tabular}

Abbreviations: BAL, bronchoalveolar lavage; h, human; IFN- $\gamma$, interferon-gamma; IL, interleukin; m, mouse; NKTs, natural killer T cells; Th, T-helper. 
function; however, to date, such compounds have not been reported.

\section{A role for TIM-2 in respiratory disease}

Given that TIM-2, unlike the other TIM proteins discussed in this review, is not expressed in humans, the potential of this molecule to be a therapeutic target in human lung disease is very limited. Nevertheless, several studies support the role of TIM-2 as a modulator of Th-2 responses in mouse models. Blockade of TIM-2 with recombinant TIM-2 (TIM-2-Ig) was sufficient to mount a Th-2 immune response and ameliorate disease progression in a model of autoimmune encephalitis. Additionally, the TIM-2 knockout murine model displays an exacerbated Th-2-driven response in a model of ovalbumininduced airway inflammation. ${ }^{7}$ Semaphorin-4A is a recognized TIM-2 ligand, ${ }^{79}$ yet semaphorin-4A-deficient mice develop exaggerated Th-2 phenotypes, supporting TIM-2 as an inhibitor of Th-2 responses. ${ }^{80}$ TIM-2 was also identified as a specific heavy chain ferritin (H-ferritin) receptor leading to endocytosis of extracellular $\mathrm{H}$-ferritin in liver $^{81}$ and brain. ${ }^{82} \mathrm{H}$-ferritin has been reported to display immunological properties, mainly as a regulator of proliferation and differentiation of immune cells. ${ }^{83}$ Interestingly, elevated levels of $\mathrm{H}$-ferritin were found in cystic fibrosis BAL fluid compared with levels found in other inflammatory respiratory conditions. ${ }^{84} \mathrm{~A}$ link between high levels of ferritin and altered TIM expression has been suggested but not formally demonstrated. ${ }^{5}$ Nevertheless, none of the human TIM receptors appear to bind H-ferritin. ${ }^{27}$ Since murine TIM-2 does not have a human ortholog, ${ }^{24}$ whether another human TIM receptor can adopt the Th-2 inhibitory function described in mice ${ }^{85}$ remains to be elucidated.

\section{TIM-3 and airway infection and disease}

TIM-3 has also been implicated in the development of asthma (Table 1). Given the role of TIM-3 as a negative regulator of Th-1 mediated immunity, blockade of TIM-3 may prove useful in the treatment of this disease. Indeed, blockade of TIM-3 with a specific antibody reduced airway hyperreactivity and induced a switch from Th-2- to Th-1-type response in a murine experimental model. ${ }^{86}$ Consistent with these results, expression of TIM-3 in CD4+ cells was increased after ovalbumin challenge in a mouse model of asthma, ${ }^{87}$ further supporting TIM-3 as a negative regulator of Th-1 mediated immunity. In line with the described TIM-3 function, low levels of TIM-3 expression in CD4+ cells from peripheral blood and BAL were correlated with an increased Th-1-type immune response in sarcoidosis, ${ }^{77}$ a prototypical
Th-1 inflammatory disease. Additionally, the role of TIM-3 as a phosphatidylserine receptor has been suggested to be involved in the development of airway hyperresponsiveness, as efficient clearance of apoptotic cells is crucial in preventing development of atopy. ${ }^{88}$ Thus, targeting the TIM-3 inhibitory pathway may represent a novel approach to restore the Th-1/Th-2 response balance in airway disease.

TIM-3 has also been suggested to be involved in the regulation of the inflammatory response to airway infection. In a mouse model of Klebsiella pneumoniae-induced pneumonia, administration of galectin-9 induced apoptosis of Th-17 cells and reduction of IL-17 generation, which, in this model, proved crucial for bacterial clearance in the lung. Decreased IL-17 production led to impaired neutrophil recruitment into the airways with subsequent reduced bacterial clearance and higher mortality. ${ }^{89}$ These results suggest an important role for TIM-3/galectin-9 in termination of Th-17-mediated immune responses. Regulation of TIM-3 function in CD8 T cells was shown to be critical to mount an adequate immune response against viral infection. ${ }^{90}$ Blockade of TIM-3-galectin-9 interaction by administration of a recombinant TIM-3 protein improved the immune response in a mouse model of influenza A virus infection..$^{90}$ Moreover, galectin-9 knockout mice were refractory to influenza A virus infection. Taking these results together, the indication is that Tim-3-galectin-9 interaction works to limit the extent and potency of the $\mathrm{T}$ cell responses to pathogen infection. Since TIM-3 function has proved to be critical during infection, targeting the TIM-3/galectin-9 pathway may be a viable approach. It is worth noting that the level of inhibition appears to be crucial, as it should effectively limit an exacerbated inflammatory response but should avoid an excessive repression of the immune response that could result in defective pathogen clearance. Thus, the TIM-3 targeting agent should preferably be delivered locally rather than systemically.

TIM-3 and its ligand galectin-9 were found to be constitutively overexpressed in human bronchial epithelium from cystic fibrosis patients. ${ }^{91}$ Both ligand and receptor were further expressed following exposure to lipopolysaccharide from Pseudomonas aeruginosa, which emphasizes the role of TIM-3 under inflammatory conditions. However, in the cystic fibrosis lung, both TIM-3 and its ligand galectin-9 undergo rapid degradation by neutrophil-derived proteases in particular, neutrophil elastase and proteinase 3 - potentially contributing to the defective bacterial clearance observed within the cystic fibrosis lung despite the high neutrophilic presence. In line with these observations, in addition to targeted delivery of the TIM-3 effector molecule to the lungs, 
this molecule should be designed to be resistant to proteolytic cleavage to be an effective agent.

The role of TIM-3 in pathogen infection goes beyond orchestration of the humoral and cellular immune responses. A novel role for TIM-3 in airway infection was recently revealed: ${ }^{12}$ in this study, TIM-3 was shown to act as a ligand and to stimulate galectin-9 expressed on the surface of macrophages. Through unidentified mechanisms, galectin- 9 engagement on infected macrophages triggered IL- $1 \beta$ production and subsequent Mycobacterium tuberculosis intracellular clearance. The study, by Jayaraman and colleagues, suggested that TIM-3 expressed on Th-1 cells can modulate macrophage-mediated bacterial killing. ${ }^{12}$ This constitutes the first report on the role of TIM-3 as a ligand, in addition to the prototypical role as a Th-1 receptor capable of modulating the inflammatory response. These studies open a new area of TIM-3 research on the role of this molecule in bacterial infection.

\section{Galectin-9 in airway disease}

Galectin-9 has been shown to be involved in airway disease via TIM-3-dependent and -independent mechanisms (Table 2). Galectin-9 expression was found to be elevated in lung tissue in animal models of asthma. ${ }^{61,92}$ This overexpression of galectin-9 was found to correlate with an increase in Th-2 cytokines and increased cell counts in the lungs, particularly eosinophils. A similar correlation between elevated galectin-9 and high eosinophil counts was reported in patients with acute and chronic eosinophilic pneumonia. ${ }^{93}$ Interestingly, administration of recombinant galectin-9 attenuated lung inflammation in a mouse model of asthma, which highlights the use of recombinant galectin-9 as a promising therapeutic agent. ${ }^{69}$ In this study, galectin-9 inhibited mast-cell degranulation by disrupting IgE/antigen complex formation. Recombinant galectin-9 administration also ameliorated lung inflammation in a mouse model of asthma due to inhibition of CD44-hyaluronic acid interaction, which is required for recruitment of leukocytes into the airways. ${ }^{67}$ The study also showed that galectin-9 can induce apoptosis of eosinophils, thereby reducing disease severity in this asthma model.

Galectin-9 has been shown to affect antimicrobial immunity in two distinct manners. First, galectin-9 stimulates immune responses via recruitment of immune cells. Secondly, galectin- 9 can limit the adaptive immune response, in particular, the $\mathrm{T}$ cell response, while promoting the expansion of regulatory cells. ${ }^{94}$ Of interest, a recent publication reported a novel role for galectin-9 in antimicrobial immunity. ${ }^{12}$ This
Table 2 Galectin-9 in airway disease

\begin{tabular}{|c|c|c|}
\hline Disease & Function & References \\
\hline \multicolumn{3}{|l|}{ Asthma } \\
\hline g & $\begin{array}{l}\text { Galectin- } 9 \text { levels increased in an allergic AHR } \\
\text { model and correlated with eosinophil counts }\end{array}$ & 92 \\
\hline $\mathrm{m}$ & $\begin{array}{l}\text { Galectin-9 levels increased in an allergic AHR } \\
\text { model and correlated with eosinophil counts }\end{array}$ & 61 \\
\hline$g$ & $\begin{array}{l}\text { Galectin- } 9 \text { administration attenuated allergic } \\
\text { inflammation by binding lgE and reducing } \\
\text { mast cell degranulation }\end{array}$ & 69 \\
\hline $\mathrm{m}$ & $\begin{array}{l}\text { Galectin- } 9 \text { administration attenuated } A H R \\
\text { and allergic inflammation binding to CD44, } \\
\text { which reduced } T \text { cell migration }\end{array}$ & 67 \\
\hline \multicolumn{3}{|c|}{ Lung cancer } \\
\hline $\mathrm{m}$ & $\begin{array}{l}\text { Galectin-9 administration reduced tumor } \\
\text { cell migration }\end{array}$ & 68 \\
\hline $\mathrm{m}$ & $\begin{array}{l}\text { Galectin- } 9 \text { administration prolonged survival in } \\
\text { a lung cancer model by induction of macrophage } \\
\text { differentiation into dendritic-like cells that } \\
\text { promote activation of natural killing cells }\end{array}$ & 95 \\
\hline \multicolumn{3}{|c|}{ Acute lung injury } \\
\hline $\mathrm{m}$ & $\begin{array}{l}\text { Galectin- } 9 \text { administration ameliorated acute } \\
\text { lung injury expanding regulatory macrophages }\end{array}$ & 94 \\
\hline \multicolumn{3}{|c|}{ Tuberculosis } \\
\hline $\mathrm{m} / \mathrm{h}$ & $\begin{array}{l}\text { TIM-3 interacted with galectin- } 9 \text { on macrophages } \\
\text { to restrict intracellular bacterial growth }\end{array}$ & 12 \\
\hline \multicolumn{3}{|c|}{ Cystic fibrosis } \\
\hline h & $\begin{array}{l}\text { Constitutive upregulation in bronchial epithelial } \\
\text { cells induced IL-8 production }\end{array}$ & 91 \\
\hline \multicolumn{3}{|c|}{ Pneumonia } \\
\hline $\mathrm{m}$ & $\begin{array}{l}\text { Galectin- } 9 \text { intraperitoneal administration } \\
\text { reduced IL- I } 7 \text { production and reduced } \\
\text { bacterial clearance }\end{array}$ & 89 \\
\hline h & $\begin{array}{l}\text { Galectin- } 9 \text { levels correlated with eosinophil } \\
\text { counts in acute and chronic eosinophilic } \\
\text { pneumonia }\end{array}$ & 93 \\
\hline \multicolumn{3}{|c|}{ Sarcoidosis } \\
\hline h & Galectin-9 levels not altered in Th cells & 77 \\
\hline \multicolumn{3}{|c|}{ Influenza } \\
\hline $\mathrm{m}$ & $\begin{array}{l}\text { Galectin- } 9 \text { knockout mice mounted a higher } \\
\text { response to influenza A virus infection }\end{array}$ & 90 \\
\hline
\end{tabular}

Abbreviations: AHR, airway hyperresponsiveness; g, guinea pig; h, human; Ig, immunoglobulin; IL, interleukin; m, mouse; Th, T-helper.

latter study described for the first time a reversal of TIM-3/ galectin-9 signaling pathway whereby galectin-9 acted as a receptor in infected macrophages and was stimulated via interactions with TIM-3 expressed on adjacent Th-1 cells.

\section{Conclusion}

The data described so far emphasize a role for TIM-containing molecules as modulators of the immune response in the airways. TIM-containing molecules emerge as ideal candidates for therapeutic intervention in the lung at several levels. First, TIM-containing molecules may effect the inflammatory response in the airways due to their direct role in promot- 
ing generation of pro- and anti-inflammatory mediators. Secondly, TIM-containing molecules may act as regulators of cellular homeostasis in the lung via induction of selective apoptosis of immune cells and preferential expansion of regulatory cells via galectin- 9 interactions. Additionally, TIM-containing molecules may also help fight lung infections, as they have been shown to be involved in viral recognition and phagocytic cell function. Therefore, manipulation of the TIM-regulated mechanisms may prove beneficial in human airway disease. TIM pathways may be modulated by specific antibodies directed towards well-defined regions of the receptor, recombinant proteins containing the precise agonist/ antagonist motifs, or small-molecule drugs. In addition, treatments aimed at modulating TIM-regulated pathways should consider delivery of newly developed drugs to specific areas in the body for localized treatment.

\section{Acknowledgments}

Preparation of this article was supported by grants from the Health Research Board Ireland (grant number PHD/2007/11) and the Program for Research in Third Level Institutes (PRTLI) administered by the Higher Education Authority.

\section{Disclosure}

None of the authors has a financial relationship with a commercial entity that has an interest in the subject of the presented manuscript.

\section{References}

1. Wang Y, Meng J, Wang X, et al. Expression of human TIM-1 and TIM-3 on lymphocytes from systemic lupus erythematosus patients. Scand $J$ Immunol. 2008;67(1):63-70.

2. Kuchroo VK, Dardalhon V, Xiao S, Anderson AC. New roles for TIM family members in immune regulation. Nat Rev Immunol. 2008;8(8): $577-580$.

3. Su EW, Lin JY, Kane LP. TIM-1 and TIM-3 proteins in immune regulation. Cytokine. 2008;44(1):9-13.

4. Rodriguez-Manzanet R, DeKruyff R, Kuchroo VK, Umetsu DT. The costimulatory role of TIM molecules. Immunol Rev. 2009;229(1): 259-270.

5. Recalcati S, Invernizzi P, Arosio P, Cairo G. New functions for an iron storage protein: the role of ferritin in immunity and autoimmunity. J Autoimmun. 2008;30(1-2):84-89.

6. Seki M, Oomizu S, Sakata KM, et al. Galectin-9 suppresses the generation of Th17, promotes the induction of regulatory $\mathrm{T}$ cells, and regulates experimental autoimmune arthritis. Clin Immunol. 2008; 127(1):78-88.

7. Rennert PD, Ichimura T, Sizing ID, et al. T cell, Ig domain, mucin domain-2 gene-deficient mice reveal a novel mechanism for the regulation of Th2 immune responses and airway inflammation. J Immunol. 2006;177(7):4311-4321.

8. Khademi M, Illés Z, Gielen AW, et al. T Cell Ig- and mucin-domaincontaining molecule-3 (TIM-3) and TIM-1 molecules are differentially expressed on human Th1 and Th2 cells and in cerebrospinal fluidderived mononuclear cells in multiple sclerosis. J Immunol. 2004; 172(11):7169-7176.
9. Sánchez-Fueyo A, Tian J, Picarella D, et al. Tim-3 inhibits T helper type 1-mediated auto- and alloimmune responses and promotes immunological tolerance. Nat Immunol. 2003;4(11):1093-1101.

10. Ngiow SF, von Scheidt B, Akiba H, Yagita H, Teng MW, Smyth MJ. Anti-TIM3 antibody promotes T cell IFN- $\gamma$-mediated antitumor immunity and suppresses established tumors. Cancer Res. 2011;71(10): 3540-3451.

11. Sakuishi K, Jayaraman P, Behar SM, Anderson AC, Kuchroo VK. Emerging Tim-3 functions in antimicrobial and tumor immunity. Trends Immunol. 2011;32(8):345-349.

12. Jayaraman P, Sada-Ovalle I, Beladi S, et al. Tim3 binding to galectin-9 stimulates antimicrobial immunity. J Exp Med.2010;207(11): 2343-2354.

13. MEDLINE ${ }^{\circledR}$ [database on the Internet]. Bethesda, MD: National Library of Medicine; nd. Available from: http://www.ncbi.nlm.nih. gov/pubmed/. Accessed July 18, 2012.

14. Google Scholar [web search engine on the Internet]. Moutain View, CA: Google; nd. Available from: http://www.scholar.google.com. Accessed July 18, 2012.

15. The Cochrane Library [database on the Internet]. Hoboken, NJ: John Wiley and Sons; 2012. Available from: http://www.thecochranelibrary. com/view/0/index.html. Accessed July 18, 2012.

16. Meyers JH, Sabatos CA, Chakravarti S, Kuchroo VK. The TIM gene family regulates autoimmune and allergic diseases. Trends Mol Med. 2005;11(8):362-369.

17. Santiago C, Ballesteros A, Tami C, Martínez-Muñoz L, Kaplan GG, Casasnovas JM. Structures of T Cell immunoglobulin mucin receptors 1 and 2 reveal mechanisms for regulation of immune responses by the TIM receptor family. Immunity. 2007;26(3):299-310.

18. Kaplan G, Totsuka A, Thompson P, Akatsuka T, Moritsugu Y, Feinstone SM. Identification of a surface glycoprotein on African green monkey kidney cells as a receptor for hepatitis A virus. EMBO J. 1996;15(16):4282-4296.

19. Feigelstock D, Thompson P, Mattoo P, Zhang Y, Kaplan GG. The human homolog of HAVcr-1 codes for a hepatitis A virus cellular receptor. J Virol. 1998;72(8):6621-6628.

20. Ichimura T, Bonventre JV, Bailly V, et al. Kidney injury molecule-1 (KIM-1), a putative epithelial cell adhesion molecule containing a novel immunoglobulin domain, is up-regulated in renal cells after injury. J Biol Chem. 1998;273(7):4135-4142.

21. Bailly V, Zhang Z, Meier W, Cate R, Sanicola M, Bonventre JV. Shedding of kidney injury molecule-1, a putative adhesion protein involved in renal regeneration. J Biol Chem. 2002;277(42):39739-39748.

22. Han WK, Bailly V, Abichandani R, Thadhani R, Bonventre JV. Kidney Injury Molecule-1 (KIM-1): a novel biomarker for human renal proximal tubule injury. Kidney Int. 2002;62(1):237-244.

23. Encinas JA, Janssen EM, Weiner DB, et al. Anti-T-cell Ig and mucin domain-containing protein 1 antibody decreases TH2 airway inflammation in a mouse model of asthma. J Allergy Clin Immunol. 2005;116(6): $1343-1349$

24. Knickelbein JE, de Souza AJ, Tosti R, Narayan P, Kane LP. Cutting edge: inhibition of T cell activation by TIM-2.J Immunol. 2006;177(8): 4966-4970.

25. Kobayashi N, Karisola P, Peña-Cruz V, et al. TIM-1 and TIM-4 glycoproteins bind phosphatidylserine and mediate uptake of apoptotic cells. Immunity. 2007;27(6):927-940.

26. Miyanishi M, Tada K, Koike M, Uchiyama Y, Kitamura T, Nagata S. Identification of Tim4 as a phosphatidylserine receptor. Nature. 2007; 450(7168):435-439

27. Freeman GJ, Casasnovas JM, Umetsu DT, DeKruyff RH. TIM genes: a family of cell surface phosphatidylserine receptors that regulate innate and adaptive immunity. Immunol Rev. 2010;235(1): $172-189$.

28. van de Weyer PS, Muehlfeit M, Klose C, Bonventre JV, Walz G, Kuehn EW. A highly conserved tyrosine of Tim-3 is phosphorylated upon stimulation by its ligand galectin-9. Biochem Biophys Res Commun. 2006;351(2):571-576. 
29. Lee J, Su EW, Zhu C, et al. Phosphotyrosine-dependent coupling of Tim-3 to T-cell receptor signalling pathways. Mol Cell Biol. 2011;31(19):3963-3974.

30. Zhu C, Anderson AC, Schubart A, et al. The Tim-3 ligand galectin-9 negatively regulates $\mathrm{T}$ helper type 1 immunity. Nat Immunol. 2005; 6(12):1245-1252.

31. Monney L, Sabatos CA, Gaglia JL, et al. Th1-specific cell surface protein Tim-3 regulates macrophage activation and severity of an autoimmune disease. Nature. 2002;415(6871):536-541.

32. Hastings WD, Anderson DE, Kassam N, et al. TIM-3 is expressed on activated human CD4+ T cells and regulates Th1 and Th17 cytokines. Eur J Immunol. 2009;39(9):2492-2501.

33. Sabatos CA, Chakravarti S, Cha E, et al. Interaction of Tim-3 and Tim-3 ligand regulates $\mathrm{T}$ helper type 1 responses and induction of peripheral tolerance. Nat Immunol. 2003;4(11):1102-1110.

34. Oikawa T, Kamimura Y, Akiba H, et al. Preferential involvement of Tim-3 in the regulation of hepatic CD8+ T cells in murine acute graftversus-host disease. J Immunol. 2006;177(7):4281-4287.

35. Nakayama M, Akiba H, Takeda K, et al. Tim-3 mediates phagocytosis of apoptotic cells and cross-presentation. Blood. 2009;113(16): 3821-3830

36. Zhao J, Lei Z, Liu Y, et al. Human pregnancy up-regulates Tim-3 in innate immune cells for systemic immunity. J Immunol. 2009;182(10): 6618-6624.

37. Ichimura T, Asseldonk EJ, Humphreys BD, Gunaratnam L, Duffield JS, Bonventre JV. Kidney injury molecule-1 is a phosphatidylserine receptor that confers a phagocytic phenotype on epithelial cells. J Clin Invest. 2008;118(5):1657-1668.

38. Rabinovich GA, Liu FT, Hirashima M, Anderson A. An emerging role for galectins in tuning the immune response: lessons from experimental models of inflammatory disease, autoimmunity and cancer. Scand $J$ Immunol. 2007;66(2-3):143-158.

39. Paroutaud P, Levi G, Teichberg VI, Strosberg AD. Extensive amino acid sequence homologies between animal lectins. Proc Natl Acad Sci U S A. 1987;84(18):6345-6348.

40. Cummings RD, Liu FT. Galectins. In: Varki A, Cummings RD, Esko JD, et al, editors. Essentials of Glycobiology [book on the Internet]. 2nd ed. Cold Spring Harbor, NY: Cold Spring Harbour Laboratory Press, 2009. Available from: http://www.ncbi.nlm.nih.gov/books/NBK1944/. Accessed July 18, 2012.

41. Chabot S, Kashio Y, Seki M, et al. Regulation of galectin-9 expression and release in Jurkat T cell line cells. Glycobiology. 2002;12(2): 111-118.

42. Nishi N, Itoh A, Fujiyama A, et al. Development of highly stable galectins: truncation of the linker peptide confers protease-resistance on tandem-repeat type galectins. FEBS Lett. 2005;579(10): 2058-2064.

43. Matsushita N, Nishi N, Seki M, et al. Requirement of divalent galactoside-binding activity of ecalectin/galectin-9 for eosinophil chemoattraction. J Biol Chem. 2000;275(12):8355-8360.

44. Wada J, Kanwar YS. Identification and characterization of galectin-9, a novel beta-galactoside-binding mammalian lectin. J Biol Chem. 1997;272(9):6078-6086.

45. Matsumoto R, Matsumoto H, Seki M, et al. Human ecalectin, a variant of human galectin-9, is a novel eosinophil chemoattractant produced by T lymphocytes. J Biol Chem. 1998;273(27):16976-16984.

46. Shimizu Y, Kabir-Salmani M, Azadbakht M, Sugihara K, Sakai K, Iwashita M. Expression and localization of galectin-9 in the human uterodome. Endocr J. 2008;55(5):879-887.

47. Liang M, Ueno M, Oomizu S, et al. Galectin-9 expression links to malignant potential of cervical squamous cell carcinoma. J Cancer Res Clin Oncol. 2008;134(8):899-907.

48. Pielage JF, Cichon C, Greune L, Hirashima M, Kucharzik T, Schmidt MA. Reversible differentiation of Caco- 2 cells reveals galectin- 9 as a surface marker molecule for human follicle-associated epithelia and M cell-like cells. Int J Biochem Cell Biol. 2007;39(10):1886-1901.
49. Park WS, Jung WK, Park SK, et al. Expression of galectin- 9 by IFN- $\gamma$ stimulated human nasal polyp fibroblasts through MAPK, PI3K, and JAK/STAT signaling pathways. Biochem Biophys Res Commun. 2011;411(2):259-264.

50. Kasamatsu A, Uzawa K, Shimada K, et al. Elevation of galectin-9 as an inflammatory response in the periodontal ligament cells exposed to Porphylomonas gingivalis lipopolysaccharide in vitro and in vivo. Int J Biochem Cell Biol. 2005;37(2):397-408.

51. Pioche-Durieu $C$, Keryer $C$, Souquère $S$, et al. In nasopharyngeal carcinoma cells, Epstein-Barr virus LMP1 interacts with galectin 9 in membrane raft elements resistant to simvastatin. J Virol. 2005;79(21): 13326-13337.

52. Ishikawa A, Imaizumi $\mathrm{T}$, Yoshida $\mathrm{H}$, et al. Double-stranded RNA enhances the expression of galectin-9 in vascular endothelial cells. Immunol Cell Biol. 2004;82(4):410-414.

53. Imaizumi $\mathrm{T}$, Kumagai $\mathrm{M}$, Sasaki $\mathrm{N}$, et al. Interferon-gamma stimulates the expression of galectin-9 in cultured human endothelial cells. $J$ Leukoc Biol. 2002;72(3):486-491.

54. Wiener Z, Kohalmi B, Pocza P, et al. TIM-3 is expressed in melanoma cells and is upregulated in TGF-beta stimulated mast cells. $J$ Invest Dermatol. 2007;127(4):906-914.

55. Spitzenberger F, Graessler J, Schroeder HE. Molecular and functional characterization of galectin $9 \mathrm{mRNA}$ isoforms in porcine and human cells and tissues. Biochimie. 2001;83(9):851-862.

56. Mengshol JA, Golden-Mason L, Arikawa T, et al. A crucial role for Kupffer cell-derived galectin-9 in regulation of T cell immunity in hepatitis C infection. PLoS One. 2010;5(3):e9504.

57. Stancic M, van Horssen J, Thijssen VL, et al. Increased expression of distinct galectins in multiple sclerosis lesions. Neuropathol Appl Neurobiol. 2011;37(6):654-671.

58. Yoshida $\mathrm{H}$, Imaizumi T, Kumagai M, et al. Interleukin-1beta stimulates galectin-9 expression in human astrocytes. Neuroreport. 2001;12(17): 3755-3758.

59. Dietz AB, Bulur PA, Knutson GJ, Matasic R, Vuk-Pavlovic S. Maturation of human monocyte-derived dendritic cells studied by microarray hybridization. Biochem Biophys Res Commun. 2000;275(3): 731-738.

60. Elahi S, Dinges WL, Lejarcegui N, et al. Protective HIV-specific CD8+ T cells evade Treg cell suppression. Nat Med. 2011;17(8): 989-995.

61. Sziksz E, Kozma GT, Pállinger E, et al. Galectin-9 in allergic airway inflammation and hyper-responsiveness in mice. Int Arch Allergy Immunol. 2010;151(4):308-317.

62. Abedin MJ, Kashio Y, Seki M, Nakamura K, Hirashima M. Potential roles of galectins in myeloid differentiation into three different lineages. J Leukoc Biol. 2003;73(5):650-656.

63. Saita N, Goto E, Yamamoto T, et al. Association of galectin-9 with eosinophil apoptosis. Int Arch Allergy Immunol. 2002;128(1):42-50.

64. Toscano MA, Ilarregui JM, Bianco GA, et al. Dissecting the pathophysiologic role of endogenous lectins: glycan-binding proteins with cytokine-like activity? Cytokine Growth Factor Rev. 2007;18(1-2): $57-71$.

65. Anderson AC, Anderson DE, Bregoli L, et al. Promotion of tissue inflammation by the immune receptor Tim-3 expressed on innate immune cells. Science. 2007;318(5853):1141-1143.

66. Zhu C, Anderson AC, Kuchroo VK. TIM-3 and its regulatory role in immune responses. Curr Top Microbiol Immunol. 2011;350:1-15.

67. Katoh S, Ishii N, Nobumoto A, et al. Galectin-9 inhibits CD44-hyaluronan interaction and suppresses a murine model of allergic asthma. Am J Respir Crit Care Med. 2007;176(1):27-35.

68. Nobumoto A, Nagahara K, Oomizu S, et al. Galectin-9 suppresses tumor metastasis by blocking adhesion to endothelium and extracellular matrices. Glycobiology. 2008;18(9):735-744.

69. Niki T, Tsutsui S, Hirose $\mathrm{S}$, et al. Galectin-9 is a high affinity IgEbinding lectin with anti-allergic effect by blocking IgE-antigen complex formation. J Biol Chem. 2009;284(47):32344-32352. 
70. Ohtsubo K, Takamatsu S, Minowa MT, Yoshida A, Takeuchi M, Marth JD. Dietary and genetic control of glucose transporter 2 glycosylation promotes insulin secretion in suppressing diabetes. Cell. 2005;123(7):1307-1321

71. McIntire JJ, Umetsu SE, Akbari O, et al. Identification of Tapr (an airway hyperreactivity regulatory locus) and the linked Tim gene family. Nat Immunol. 2001;2(12):1109-1116.

72. Barlow JL, Wong SH, Ballantyne SJ, Jolin HE, McKenzie AN. Tim1 and Tim3 are not essential for experimental allergic asthma. Clin Exp Allergy. 2011;41(7):1012-1021.

73. Xu G, Cheng L, Lu L, et al. Expression of T-cell immunoglobulinand mucin-domain-containing molecule-1 (TIM-1) is increased in a mouse model of asthma and relationship to GATA-3. Life Sci. 2008; 82(11-12):663-669.

74. Umetsu SE, Lee WL, McIntire JJ, et al. TIM-1 induces T cell activation and inhibits the development of peripheral tolerance. Nat Immunol. 2005;6(5):447-454.

75. Sizing ID, Bailly V, McCoon P, et al. Epitope-dependent effect of anti-murine TIM-1 monoclonal antibodies on T cell activity and lung immune responses. J Immunol. 2007;178(4):2249-2261.

76. Sonar SS, Hsu YM, Conrad ML, et al. Antagonism of TIM-1 blocks the development of disease in a humanized mouse model of allergic asthma. J Clin Invest. 2010;120(8):2767-2781.

77. Idali F, Wahlström J, Dahlberg B, et al. Altered expression of T cell immunoglobulin-mucin (TIM) molecules in bronchoalveolar lavage CD4+ T cells in sarcoidosis. Respir Res. 2009;10:42.

78. Kim HS, Kim HS, Lee CW, Chung DH. T cell Ig domain and mucin domain 1 engagement on invariant NKT cells in the presence of TCR stimulation enhances IL-4 production but inhibits IFN-gamma production. J Immunol. 2010;184(8):4095-4106.

79. Kumanogoh A, Marukawa S, Suzuki K, et al. Class IV semaphorin Sema4 A enhances T-cell activation and interacts with Tim-2. Nature. 2002;419(6907):629-633.

80. Takamatsu H, Okuno T, Kumanogoh A. Regulation of immune cell responses by semaphorins and their receptors. Cell Mol Immunol. 2010; 7(2):83-88.

81. Chen TT, Li L, Chung DH, et al. TIM-2 is expressed on B cells and in liver and kidney and is a receptor for $\mathrm{H}$-ferritin endocytosis. $J$ Exp Med. 2005;202(7):955-965.

82. Todorich B, Zhang X, Slagle-Webb B, Seaman WE, Connor JR. Tim-2 is the receptor for H-ferritin on oligodendrocytes. J Neurochem. 2008;107(6):1495-1505.
83. Morikawa K, Oseko F, Morikawa S. A role for ferritin in hematopoiesis and the immune system. Leuk Lymphoma. 1995;18(6):429-433.

84. Stites SW, Plautz MW, Bailey K, O’Brien-Ladner AR, Wesselius LJ. Increased concentrations of iron and isoferritins in the lower respiratory tract of patients with stable cystic fibrosis. Am J Respir Crit Care Med. 1999;160(3):796-801.

85. Chakravarti S, Sabatos CA, Xiao S, et al. Tim-2 regulates T helper type 2 responses and autoimmunity. J Exp Med. 2005;202(3):437-444.

86. Kearley J, McMillan SJ, Lloyd CM. Th2-driven, allergen-induced airway inflammation is reduced after treatment with anti-Tim-3 antibody in vivo. J Exp Med. 2007;204(6):1289-1294.

87. Hu WK, Lu XX, Yang S, et al. Expression of the Th1-specific cellsurface protein Tim-3 increases in a murine model of atopic asthma. J Asthma. 2009;46(9):872-877.

88. DeKruyff RH, Bu X, Ballesteros A, et al. T cell/transmembrane, Ig, and mucin-3 allelic variants differentially recognize phosphatidylserine and mediate phagocytosis of apoptotic cells. J Immunol. 2010;184(4): 1918-1930.

89. Wang $\mathrm{F}, \mathrm{Xu}$ J, Liao Y, et al. Tim-3 ligand galectin-9 reduces IL-17 level and accelerates Klebsiella pneumoniae infection. Cell Immunol. 2011;269(1):22-28

90. Sharma S, Sundararajan A, Suryawanshi A, et al. T cell immunoglobulin and mucin protein-3 (Tim-3)/Galectin-9 interaction regulates influenza A virus-specific humoral and CD8 T-cell responses. Proc Natl Acad Sci U S A. 2011;108(47):19001-19006.

91. Vega-Carrascal I, Reeves EP, Niki T, et al. Dysregulation of TIM-3galectin-9 pathway in the cystic fibrosis airways. J Immunol. 2011; 186(5):2897-2909.

92. Yamamoto H, Kashio Y, Shoji H, et al. Involvement of galectin-9 in guinea pig allergic airway inflammation. Int Arch Allergy Immunol. 2007;143 Suppl 1:95-105.

93. Katoh S, Nobumoto A, Matsumoto N, et al. Involvement of galectin-9 in lung eosinophilia in patients with eosinophilic pneumonia. Int Arch Allergy Immunol. 2010;153(3):294-302.

94. Kojima K, Arikawa T, Saita N, et al. Galectin-9 attenuates acute lung injury by expanding CD14-plasmacytoid dendritic cell-like macrophages. Am J Respir Crit Care Med. 2011;184(3):328-339.

95. Kadowaki T, Arikawa T, Shinonaga R, et al. Galectin-9 signaling prolongs survival in murine lung-cancer by inducing macrophages to differentiate into plasmacytoid dendritic cell-like macrophages. Clin Immunol. 2012;142(3):296-307.
Journal of Inflammation Research

\section{Publish your work in this journal}

The Journal of Inflammation Research is an international, peer-reviewed open-access journal that welcomes laboratory and clinical findings on the molecular basis, cell biology and pharmacology of inflammation including original research, reviews, symposium reports, hypothesis formation and commentaries on: acute/chronic inflammation; mediators of inflamma-

\section{Dovepress}

tion; cellular processes; molecular mechanisms; pharmacology and novel anti-inflammatory drugs; clinical conditions involving inflammation. The manuscript management system is completely online and includes a very quick and fair peer-review system. Visit http://www.dovepress.com/ testimonials.php to read real quotes from published authors. 